\title{
Chronic disease as risk multiplier for disadvantage
}

Francisca Stutzin Donoso

\begin{abstract}
This paper starts by establishing a prima facie case that disadvantaged groups or individuals are not only more likely to get a chronic disease but also in a disadvantaged position to adhere to chronic treatment despite access through Universal Health Coverage. However, the main aim of this paper is to explore the normative implications of this claim by examining two different but intertwined argumentative lines that might contribute to a better understanding of the ethical challenges faced by chronic disease health policy. The paper develops the argument that certain disadvantages which may predispose to illness might overlap with disadvantages that may hinder self-management, potentially becoming disadvantages in handling chronic disease. If so, chronic diseases may be seen as disadvantages in themselves, describing a reproduction of disadvantage amongst the chronically ill and a vicious circle of disadvantage that could both predict and shed light on the catastrophic health outcomes amongst disadvantaged groups-or individuals - dealing with chronic disease.
\end{abstract}

\section{INTRODUCTION}

When I worked as a clinical psychologist at the HIV/AIDS polyclinic of a public hospital in Santiago, Chile I was confronted with the fact that, on a daily basis, some of our patients died despite having access to treatment through Universal Health Coverage (UHC). Healthcare professionals would frequently say things like: "Patients have all the medical care they need to cope with this disease, if they die it's because they are silly, they do not listen, and do not follow our recommendations". ${ }^{1}$ The underlying rationale of these statements is that in a context where the state offers free care at the point of access, it is the patients' responsibility to manage their care and thus, their fault if they die from a treatable disease. This always struck me as extremely harsh -in the same line of inquiry posed by the harshness objection, which is frequently raised against luck egalitarian arguments on individual responsibility. ${ }^{1}$

HIV/AIDS is a potentially lethal infectious disease, but through highly active antiretroviral therapy (HAART) it has become a chronic illness. Evidence shows that low rates of adherence to chronic treatment for HIV/AIDS are not just a local challenge in Chile, ${ }^{2}$ but a global problem. A meta-analysis from 2011 synthesising 84 observational studies across 20 countries - including Low and Middle-Income Countries (LMICs) as well as High-Income Countries (HICs) - showed that the average reported rate of satisfactory adherence to HAART was $62 \% .{ }^{3}$ Despite relevant illness-specific characteristics, adherence to chronic treatment for all chronic diseases seems to be in crisis. The estimates are that adherence to long-term treatment for all chronic diseases is only around $50 \%$ in HICs and presumably even less in LMICs. ${ }^{4}$

The health service I worked for offered care to one of the most disadvantaged groups of patients in Santiago and the most important aspect of my job was to support and promote adherence to treatment in order to improve patients' quality of life and reduce mortality rates. Through clinical observation I confirmed the association often

1 These are recollections from my own clinical experience. 
established by researchers studying social determinants of health and chronic illness selfmanagement: that "the life situation of the patients may determine health outcomes as much as the action of healthcare professional and healthcare systems do. Access alone does not ensure benefits of available medical services". ${ }^{(p 406)}$

Analysing the experience of chronic illness and the challenges of chronic treatment adherence, I identified social isolation and psychological distress as fundamental features of my day-to-day work. From a clinical perspective, it seemed that these were not only some of the variables that may have predisposed these patients to illness in the first place but also relevant disadvantages for adhering to chronic treatment. This implies a way of thinking about the relationship between the social determinants of health and self-management of chronic illness that could be described-borrowing Wolf and de-Shalit's ${ }^{6}$ language - as the corrosive effect of certain disadvantages. From an ethical perspective, this observation gains significant weight by suggesting that access to chronic treatment might be most useful for patients who can successfully self-manage their chronic illness, doing little for those who somehow cannot.

Despite acknowledging the importance of illness-specific variables for selfmanagement, the focus of this paper is on the common core of self-management for chronic illness, ${ }^{7}$ inviting the reader to think outside the boundaries of biomedical diagnostic categories, focusing instead on the temporality that defines them: chronicity. This focus is particularly relevant for self-management tasks since these have to be indefinitely integrated by the ill subjects, determining their experience of chronic disease and its impact on the self.

The infectious/chronic division in epidemiology comprises an incompatible classification system (cause versus effect) and the intersection between the two is a neglected area in public health despite the fact that common social determinants underlie both. ${ }^{8}$ Thus, I propose that in present times, focusing on temporality of disease might offer a more comprehensive, useful and precise approach than one that conflates communicability and temporality.

The rest of this article develops the thesis that disadvantaged groups or individuals are not just more likely to have a chronic disease, but also in a disadvantaged position regarding adherence to chronic treatment. By introducing the idea that disadvantages predisposing to chronic disease may correlate with disadvantages that hinder selfmanagement of chronic illness, I will describe a vicious circle of disadvantage affecting the chronically ill and suggest that chronic illnesses become risk multipliers for disadvantage.

The first section of the article will describe how UHC systems, by mainly offering equality of opportunity for healthcare services in contexts of inequality, have failed to address the problem of chronic disease health inequalities. I stress the need to better understand the mechanisms that link social determinants of health and healthcare outcomes. The second section will explore the psycho-emotional impact of chronic illness, showing how, from a psychological perspective, it can be particularly challenging to indefinitely integrate self-management tasks and adhere to chronic treatment. Finally, the third section will aim for an integration of these perspectives, suggesting that there are good reasons to think that inequalities in adherence to treatment are correlated with and aggravate existing inequalities. Thus, drawing on Wolff and de-Shalit's ${ }^{6}$ account of disadvantage, this paper proposes a framework for interpreting and responding to 
treatment adherence inequalities in chronic diseases, extending this account by specifying their idea of disadvantage for the particular case of chronic illness.

\section{EQUALITY OF OPPORTUNITY FOR HEALTHCARE SERVICES AND CHRONIC DISEASE}

To better understand equality of opportunity for accessing healthcare services it is important to briefly consider the rights framework that supports UHC systems. The International Covenant on Economic, Social and Cultural Rights establishes a "right of everyone to the enjoyment of the highest attainable standard of physical and mental health", 9 but this definition was narrowed down in the General Comment No. 14 and operationalized as a "right to a system of health protection which provides equality of opportunity for people to enjoy the highest attainable level of health." That is, a "right to the enjoyment of a variety of facilities, goods, services and conditions necessary for the realization of the highest attainable standard of health" ${ }^{10(\mathrm{p} 3)}$ Thus, the right to health is broadly understood in terms of equality of opportunity for accessing healthcare services. However, this does not seem to be an adequate response to chronic diseases.

Noncommunicable chronic diseases are the main cause of death worldwide and, every year, almost three-quarters of these deaths occur in LMICs. ${ }^{11} 50 \%$ of all chronic disease deaths are considered premature deaths, and $82 \%$ of these premature deaths occur in LMICs. Taking into account that approximately $85 \%$ of the world's population concentrates in LMICs, ${ }^{12}$ these statistics broadly show that premature deaths caused by chronic diseases represent a significant and similar challenge across the world - in HICs and LMICs. Still, the distribution of noncommunicable chronic diseases follows Marmot's ${ }^{13}$ description of the social gradient of health, meaning that the burden of disease for these diseases tends to cluster amongst countries where economic resources are scarce and amongst the poor within wealthy societies. ${ }^{11,}{ }^{14}$ Although there are no global statistics accounting for a category of chronic diseases that includes chronic communicable diseases, it could be argued that if statistics for noncommunicable chronic diseases were to include those for chronic communicable diseases, the numbers would only add to and follow the same pattern of distribution. ${ }^{2}$ Furthermore, social determinants of health such as poor diet, sedentary lifestyle, tobacco and alcohol consumption, and social isolation have been identified as significant individual health risk factors for chronic disease. All these risks affect individuals from lower socioeconomic levels the most, following a gradient across socioeconomic groups. ${ }^{19}$ Overall, this evidence suggests that there is a pattern of unequal distribution of morbidity and mortality of chronic diseases in all societies.

Thus, UHC systems founded on a framework of equal access to healthcare have not been enough to improve populations' health as a whole and thus tackle health inequalities. ${ }^{13,20} \mathrm{~A}$ well-described and analysed example of this is the United Kingdom's (UK) National Health Service (NHS). After the UK introduced UHC in 1948, inequalities both in access to healthcare and in health outcomes across the population persisted. In fact, on the whole, the health of individuals from higher socioeconomic levels improved,

2 There is a strong association between poverty and poor environmental health and infectious diseases. ${ }^{15}$ E.g. the statistics for HIV, TB and Malaria show that these diseases are most prevalent and deadly in disadvantaged contexts. ${ }^{16-18}$ 
while the health of those of lower socioeconomic levels showed small differences. ${ }^{20}$ This is not only explained by the fact that, from a population health level, what makes people sick are socioeconomic variables that fall outside healthcare systems, but also because the better-off are able to make use of the healthcare services, while the rest of the population is not, or at least not in the same way. ${ }^{13,21}$

The fundamental cause theory of health inequalities argues that; knowledge, money, power, prestige, and beneficial social connections are key flexible resources that influence multiple disease outcomes. Access to these resources can contribute to the prevention of diseases and their negative effects, and the flexibility of these resources implies that there is a variety of mechanisms through which this can happen. ${ }^{22}$ This complex relationship between social variables and health outcomes has been used to argue for a know/do gap which causes clinical outcomes to be uneven and health disparities to persist despite effective treatments being available. ${ }^{23}$

Thus, it could be argued that, despite UHC, low treatment adherence for chronic conditions follows a social gradient that contributes to the unequal distribution of high rates of premature deaths and poor individual and population health outcomes worldwide. ${ }^{4}{ }^{24}$ Chronic patients are their own principal caregivers, which without undermining the importance of contextual variables, leads to the assumption that medical care for chronic disease frequently fails to meet different individuals' needs to effectively self-manage their disease. ${ }^{24,25}$ Of course, healthcare is still frequently structured around acute care, but this does not explain the inequalities in outcomes for people of different socioeconomic levels in managing chronic illness. ${ }^{26}$ This suggests that individuals of low socioeconomic level may have disadvantages that preclude them from effectively making use of available resources for management of chronic illness and that these disadvantages may overlap those which predisposed them to chronic illness in the first place.

Although the General Comment No. 14 acknowledges that socioeconomic inequalities play a role in health and identifies potential issues regarding accessibility, ${ }^{10}$ these do not seem to anticipate the possibility that introducing systems based on equality of opportunity in unequal contexts might exacerbate existing disadvantages.

\section{THE PSYCHO-EMOTIONAL IMPACT OF CHRONIC ILLNESS}

As I have argued, having highly effective treatments available for the management of chronic disease is not sufficient for achieving the expected chronic disease health outcomes. Improving self-management for chronic illness seems to be the key to success, however research shows that although self-management education can improve health outcomes to some extent, sustaining these improvements in the long term remains a problem. ${ }^{25}$

The individual model of self-management has been criticised for focusing predominantly on education and advice giving-reproducing a medical model that develops dependency on professionals - and paying less attention to the psychoemotional issues patients face. $^{25,27-29}$

All chronically ill patients face a common set of challenges, which imply difficult lifestyle adjustments. Some of these adjustments include complex medication regimens; obtaining helpful medical care; dealing with symptoms, disability, and emotional impacts, all of which involve significant psychological processes. ${ }^{24}$

It has been argued that in order to move beyond the burden and suffering 
associated with living with chronic diseases and effectively manage their illnesses, patients have to face a process of being transformed by the experience, aiming at the integration of new ways of being. ${ }^{30}$ This process of transformation acknowledges to some extent the deep challenges that chronic illnesses raise for human subjectivity and identity. Bury $^{31}$ suggests that the experience of chronic illness implies that "the structure of everyday life and the forms of knowledge, which underpin them, are disrupted. Chronic illness involves recognition of the worlds of pain and suffering, possibly even of death, which are normally only seen as distant possibilities or the plight of others [...]. Further expectations and plans that individuals hold for the future have to be re-examined. Thus, chronic illnesses must be regarded as critical situations, a form of biographical disruption". 31(p169)

Hence, chronic illnesses constitute the imposition of an experience that demands significant adjustments not only in terms of the day-to-day life, but also in terms of the subjectivity and identity built around a healthy self that implies a profound experience of loss. Kleinman ${ }^{32}$ argues that loss of function, self-image, and ways of living, are key psychological features of the chronicity of illness. Thus, by losing the healthy self to chronic illness, the individual losses the experience of continuity of the self, and of future expectations that were enabled by that self.

This process of subjective transformation has been argued to face significant resistance. Relying on a healthy, capable body seems to be part of the rules of the game of life, and it is inherent to subjects' daily experience. Therefore, chronic illness bursts as a betrayal of that fundamental trust in the body. ${ }^{32}$ According to MacIntyre, ${ }^{33}$ human subjectivity seems to be constituted in contrast to its organic composition, by resisting and even denying facts of disability and dependence brought by illness.

A lack of empathy towards this challenging subjective state has been argued to be one of the most painful experiences of illness, ${ }^{34}$ so another central feature of chronic illness is that individuals withdraw from social relationships, which leads to growing isolation partly because disruptions in biography are disruptions of the ability to mobilise

material resources. ${ }^{31}$ This can help explain why being well-supported by friends and/or family correlates with greater agency to implement desired health behaviour changes. ${ }^{27}$

Integrating these views about the psycho-emotional impact of chronic illness and linking them to low treatment adherence rates, I suggest that the lack of empathy might not only be experienced in social interactions with healthy people, but also in the intimacy of a disrupted subjectivity that has to cope with conflicting selves. A selfmanagement approach that pays attention to psycho-emotional issues would imply understanding that mobilising the resources needed to follow treatment, often requires being able to mourn a healthy self - a self that rejects embracing a new self that experiences itself in loss, failure, dependency. Negotiating this disruption may be a necessary step to build and embrace a new self that is willing to make the effort of following treatment, to be subject to invasive interventions, routine check-ups, and more, just to keep living or to avoid further disability.

\section{THE VICIOUS CIRCLE OF DISADVANTAGE IN THE CHRONICALLY ILL}

Taking into account the unequal distribution of chronic illness and the psychoemotional challenges raised by chronic illnesses that may hinder successful self- 
management of disease, there might be cumulative inequalities that affect the chances of successful self-management of chronic illness. Acknowledging this implies that chronic illnesses are risk multipliers for disadvantage and that a theory of the ethics of chronic disease is required. This section aims to suggest an outline for such a theory.

Wolff and de-Shalit ${ }^{6}$ propose a theory in which disadvantage is described as an intrinsically plural phenomenon, arguing that when it comes to understanding disadvantage, relations of simple direct causation and linearity do not apply. These authors' theory of disadvantage builds on the capabilities approach ${ }^{3}$ and incorporates the notion of functionings, but it proposes a relevant distinction between formal and genuine opportunity to achieve functionings to replace the concept of capability or freedom to achieve functionings. Thus, whether it is reasonable to expect something from individuals, will depend on whether they have a genuine opportunity to achieve it. ${ }^{6}$

So, would UHC by itself constitute a genuine opportunity for chronic healthcare? And, consequently, would it be reasonable to expect all patients to succeed in selfmanaging chronic illness and adhere to treatment regardless of their background and circumstances? To answer these questions, I will focus on the functioning of affiliation since it has shown to be particularly relevant to better understand chronic patients' difficulties to cope with self-management tasks.

Having a sense of belonging or affiliation makes reference to the ability to develop relationships with others, have people to rely on, feel cultural or class-related belonging amongst others, and be loved, liked and thus accepted by others. ${ }^{6}$ From an empirical perspective, affiliation has shown clear elements of clustering with the functionings of sense, imagination and thought; control over one's environment; and bodily health, thus working as one of the most fertile functionings, or corrosive disadvantages. ${ }^{6}$ Fertile in the sense that it allows overcoming disadvantage by facilitating the achievement of the other functionings, and corrosive in the sense that lacking affiliation probably implies lacking all of them. ${ }^{6}$ Furthermore, all these functionings have been argued to correlate with socioeconomic level and follow a gradient amongst socioeconomic groups. ${ }^{13}$

In this same line of argument, self-management courses experiences highlight that the main variables linked to successful outcomes are associated with creating a social context characterized by collaborative coping, shared learning, and belonging, which mainly provide a solution to the social isolation experienced by chronically ill individuals. $^{27}$ However, this might be particularly challenging considering that the chronically ill are likely to be the disadvantaged - potentially lacking fucntionings such as affiliation and all those clustering with it. Therefore, it seems ethically meaningful to consider whether these individuals are in a position of disadvantage to self-manage their disease and cope with the psychological features that have been argued to lead to even further isolation.

Following Wolff and de-Shalit's ${ }^{6}$ understanding of disadvantage, there are mainly two parameters that can determine if individuals have a genuine opportunity to make use of healthcare services and adhere to chronic treatment recommendations. These are the

3 See Nussbaum, M. Women and human development: the capabilities approach. Cambridge: Cambridge University Press 2000. 
cost that achieving one lacking functioning can have over an already achieved functioning, which depends on the individual's already achieved functioning level. ${ }^{6}$ Therefore, equality of opportunity for healthcare services might only constitute a genuine opportunity for healthcare if everyone enjoys a level of secure central functionings that is not jeopardized by making use of healthcare services.

Since the chronically ill are likely to be disadvantaged in terms of their socioeconomic level and the previously described clustering functionings, ${ }^{6,13,19}$ it would follow that the chronically ill are unlikely to enjoy a level of secure central functionings and therefore, unlikely to have a genuine opportunity to benefit from healthcare services despite having access to UHC. This implies that it would not be reasonable to expect them to comply with chronic treatment recommendations, suggesting a more complex approach to personal responsibility. Furthermore, since chronic illness diagnoses have been argued to have a negative impact on relevant functionings for chronic treatment adherence such as affiliation, there might be a cumulative effect of disadvantage leading to a vicious circle of disadvantage amongst the chronically ill. Furthermore, this implies that chronic illness diagnoses become risk multipliers for disadvantage, aggravating existing inequalities.

This brief exercise focused on broad evidence regarding affiliation and socialsupport for successful self-management of chronic illness suggests that the concepts of fertile functionings and corrosive disadvantages can be key to tackle the reproduction of disadvantage in health. Although Wolff and de-Shalit ${ }^{6}$ do not present their theory in terms of a systems theory, I propose that it could be a useful background to extend the reach of Wolff and de-Shalit's ${ }^{6}$ work and my own contributions to the ethics of chronic illness.

In general terms, systems are interconnected sets of elements or stocks aiming for a particular goal through balancing feedback loops. Although stocks are the foundation of the system and the information flowing through their interconnections is what holds the system together, inflows and outflows determine how stocks can change over time. While the behaviour of each element may be simple, their interactions will often be complex, involving multiple levels of feedback loops that serve to either balance or reinforce the behaviours of other parts of the system. ${ }^{35}$

Thus, thinking about disadvantage, chronic illness, and chronic treatment adherence in terms of interconnected elements in the form of a vicious circle or runaway loop of damage, implies adopting a systems theory perspective. From this perspective, the assumption that equality of opportunity to access healthcare services implies that individuals equally benefit from that opportunity errs in that it ignores the relevance of the relationship arising from these interacting elements. As long as there are at least two independent processing elements interacting in a system, difference is created; this is new information that is immanent in their mutual relationship of double description. ${ }^{36}$

If social and psychological resources, chronic illness, and adherence to chronic treatment are seen as stocks and flows within a system that seeks to minimise the negative effects of chronic illness, we would need to know which are the required inflows and outflows of social and psychological resources, and chronic treatment adherence to achieve this goal. Paying attention to the information arising from the interaction of these stocks - relationships - is the key to achieving dynamic equilibrium.

I have highlighted affiliation as one possible contextual feature that can contribute to a better flow of stocks, promoting the system's ability to achieve its goal. Thus, 
incorporating the idea of fertile functionings and corrosive disadvantages into a broader systems theory approach to healthcare might provide a fruitful framework to better understand the mechanisms by which information flows between myriad resources and health.

Although specific empirical investigation is required to identify fertile functionings and corrosive disadvantages affecting health outcomes in chronic illness, in advance of this enquiry, we know that social and psychological resources are stocks of which each person has a different amount before becoming ill and that those having a lower stock level are more likely to become chronically ill. Thus, the chronically ill, by being likely to have a low stock level of social and psychological resources see their chances of producing an outflow of adherence to chronic treatment recommendations reduced, leading to a vicious circle that by destroying every little stock available, leads to poor health results and further disadvantage.

\section{CONCLUSION}

This paper has argued that there are significant health inequalities that are caused -within systems of UHC - by the fact that patients' abilities to adhere to treatment for chronic diseases are widely different. This raises ethical issues relating to patients suffering avoidable morbidity and mortality as a result of uncontrolled chronic illness, and also because there are good reasons to think that inequalities in adherence to chronic treatment are correlated with, and aggravate, existing health inequalities.

Bioethicists have largely ignored inequalities that arise from differences in adherence to chronic treatment. Drawing on Wolff and de-Shalit's ${ }^{6}$ account of disadvantage, this paper proposes a framework for interpreting and responding to treatment adherence differences in chronic diseases, although it extends this account by applying their theory of disadvantage to the particular case of chronic illness. Individuals living in disadvantage in terms of their socioeconomic level and their achieved functionings level might be more likely to: 1) get a chronic illness and live shorter lives; 2) lack the functionings that could allow them to successfully self-manage their illness; and 3 ) be at risk to become more disadvantaged as a result of chronic illness.

Although this paper has no intention to dismiss the value of UHC, it does stress the need for healthcare systems to go beyond equality of opportunity for access in order to become a more effective instrument for distributive justice, highlighting the potential of adopting a systems theory perspective to do so. For the particular case of chronic illness, the argument of this article supports further empirical research on the key functionings that could facilitate better health outcomes for the chronically ill and calls for urgent revision of the distribution and compensation of these functionings through the delivery of chronic care to tackle the reproduction of disadvantage through healthcare services.

\section{REFERENCES}

1. Albertsen, A, Knight, C. A framework for luck egalitarianism in health and healthcare. $J M E$ 2015;41(2): 165-169.

2. Cohorte Chilena de SIDA. Evaluación del impacto del Programa de Acceso Expandido a Tratamiento Antiretroviral. Grupo SIDA Chile. Ministerio de Salud. 
Corporación Nacional de SIDA. [Online]. Available from:

http://web.minsal.cl/portal/url/item/85381414c60311a9e04001011e015920.pdf [Accessed 27 July 2016].

3. Ortego, C, Hudeo-Medina, B, Llorca, J, et al. Adherence to Highly Active Antiretroviral Therapy (HAART): A Meta-Analysis AIDS Behav. 2011;15:1381-1396.

4. World Health Organization. Adherence to long-term therapies: evidence for action. [Online]. Available from: http://www.who.int/chp/knowledge/publications/adherence_report/en/ [Accessed 24 August 2016].

5. Pincus, T, Esther, R, DeWalt, D, et al. Social conditions and self-management are more powerful determinants of health than access to care. Ann. Intern. Med. 1998;129(5):4064011.

6. Wolff, J, de-Shalit, A. Disadvantage. United Kingdom: Oxford University Press 2007.

7. Gallant, $\mathrm{M}$. The influence of social support on chronic illness self-management: a review and directions for research. Health Educ. Behav. 2003;30(2):170-195.

8. Choi, B, Morrison, $\mathrm{H}$, Wong, $\mathrm{T}$, et al. Bringing chronic disease epidemiology and infectious disease epidemiology back together. J. Epidemiol. Community Health 2007;61(9):802.

9. United Nations. International Covenant on Social, Economic and Cultural Rights. [Online]. Available from:

http://www.ohchr.org/EN/ProfessionalInterest/Pages/CESCR.aspx [Accessed 10 August 2016].

10. United Nations. General Comment No. 14: The Right to the Highest Attainable Standard of Health. [Online]. Available from: http://www.ohchr.org/Documents/Issues/Women/WRGS/Health/GC14.pdf [Accessed 10 August 2016]

11. World Health Organization. Fact sheet on noncommunicable diseases. [Online]. Available from: http://www.who.int/mediacentre/factsheets/fs355/en/ [Accessed 24 June 2016].

12. The World Bank Data. Population, total. [Online]. Available from: https://data.worldbank.org/indicator/SP.POP.TOTL [Accessed 28 December 2017].

13. Marmot, M. Status Syndrome: how your social standing directly affects your health. London: Bloomsbury 2005.

14. World Health Organization. Preventing chronic diseases: A vital investment. [Online]. Available from: http://www.who.int/chp/chronic disease report/full report.pdf [Accessed 22 June 2016]

15. Smith, C, Battin, M, Jacobson, J, et al. Are there characteristics of infectious diseases that raise special ethical issues? Dev World Bioeth. 2004;4(1):1-16.

16. World Health Organization. Fact sheet on HIV/AIDS [online] Available from: http://www.who.int/mediacentre/factsheets/fs360/en/ [Accessed 22 December 2016]

17. World Health Organization. Fact sheet on Tuberculosis [online] Available from: 
http://www.who.int/mediacentre/factsheets/fs104/en/ [Accessed 22 December 2016]

18. World Health Organization. Fact sheet on Malaria [online] Available from: http://www.who.int/mediacentre/factsheets/fs094/en/ [Accessed 22 December 2016]

19. Wardle, J, Steptoe, A. Socioeconomic differences in attitudes and beliefs about healthy lifestyles. J Epidemiol Community Health 2003;57(6): 440-443.

20. Whitehead, $\mathrm{M}$, Townsend, $\mathrm{P}$, Davidsen, $\mathrm{N}$, et al. Inequalities in health: the black report. The health divide. (New ed.). London: Penguin Books Ltd 1992.

21. Wolff, J. Ethics and public policy: a philosophical inquiry. London and New York: Routledge 2011.

22. Phelan, J, Link, B and Theranifar, P. Social conditions as fundamental causes of health inequalities: theory, evidence, and policy implications. J Health Soc Behav 2010;51:28-40.

23. Farmer, P. Chronic infectious disease and the future of healthcare delivery. $N$ Engl J Med 2013;369(25):2424-2436.

24. Wagner, E, Austin, B, Davis, C, et al. Improving chronic illness care: translating evidence into action. Health aff 2001;20(6):64-78.

25. Bodenheimer, $\mathrm{T}$, Lorig, $\mathrm{K}$, Halsted, $\mathrm{H}$, et al. Patient self-management of chronic disease in primary care. JAMA 2002;288(19):2469-2475.

26. Bodenheimer, T, Wagner, E, Grumbach, K. Improving primary care for patients with chronic illness. JAMA 2002;288(15):1775-1779.

27. McDonald, K, Slavin, S, Pitts, MK, et al. Chronic disease self-management by people with HIV. Qual Health Res 2016;26(6):863-870.

28. Furler, J, Walker, C, Blackberry, I, et al. The emotional context of self-management in chronic illness: A qualitative study of the role of health professional support in the selfmanagement of type 2 diabetes. BMC Health Serv Res 2008;8:214.

29. Kendall, E, Foster, M, Ehrlich, C, et al. Social processes that can facilitate and sustain individual self-management for people with chronic conditions. Nurs Res Prac 2012:1-8.

30. Dubouloz, J, King, J, Paterson, B, Ashe, B, Chevrier, J, Moldoveanu, M. A model of the process of transformation in primary care for people living with chronic illness. Chronic Illn 2010;6(4):282-293.

31. Bury, M. Chronic illness as biographical disruption. Sociol Health Illn 1982;4(2):167182.

32. Kleinman, A. The illness narratives. Suffering, healing and the human condition. United Sates of America: Basic Books 1988.

33. MacIntyre, A. Dependent rational animals: why human beings need the virtues. United Sates of America: Open Court 1999.

34. Carel, H. Illness: the cry of the flesh. Oxfordshire and New York: Routledge 2014

35. Meadows, D. Thinking in systems. A premier. United Kingdom: Earthscan 2009

36. Bateson, G. Mind and Nature. A Necessary Unity. United States of America: Hampton Press, Inc. and The Institute for Intercultural Studies 2002. 
